\title{
Extreme Moisture Flux Convergence over Western Japan during the Heavy Rain Event of July 2018
}

\author{
Kazuto Takemura ${ }^{1,2}$, Shunya Wakamatsu ${ }^{1}$, Hiroki Togawa ${ }^{1}$, Akihiko Shimpo, \\ Chiaki Kobayashi ${ }^{3}$, Shuhei Maeda ${ }^{3}$, and Hisashi Nakamura ${ }^{4}$ \\ ${ }^{1}$ Climate Prediction Division, Japan Meteorological Agency, Tokyo, Japan \\ ${ }^{2}$ Graduate School of Science, Kyoto University, Kyoto, Japan \\ ${ }^{3}$ Meteorological Research Institute, Tsukuba, Japan \\ ${ }^{4}$ Research Center for Advanced Science and Technology, the University of Tokyo, Tokyo, Japan
}

\begin{abstract}
This study investigates the influence of strong southerly moisture flux on an extreme rainfall event over western Japan in early July 2018, by using a global atmospheric reanalysis dataset. During its peak period from 5 to 7 July, extensive and unprecedented rainfall observed along the well-defined quasi-stationary Baiu front was attributed to two branches of extremely moist inflow from the southern confluence into western Japan. One was a shallow southerly airstream enhanced by the surface North Pacific Subtropical High, and the other was a deeper southwesterly airstream accompanying enhanced convection over the East China Sea. Both the vertically integrated moisture flux from the south and its convergence into western Japan reached the highest levels for 60 years due to an overwhelming contribution from the intensified southerlies. Anomalous diabatic heating associated with the active convection over the East China Sea acted to maintain the southwesterly moisture flux by inducing low-level cyclonic potential vorticity anomalies. During the rainfall event, a strong meander of the upper-level subtropical jet associated with the intensified surface North Pacific Subtropical High accompanied an amplified upper-level trough over the Korean Peninsula, which acted to induce ascent dynamically along the Baiu front.
\end{abstract}

(Citation: Takemura, K., S. Wakamatsu, H. Togawa, A. Shimpo, C. Kobayashi, S. Maeda, and H. Nakamura, 2019: Extreme moisture flux convergence over western Japan during the Heavy Rain Event of July 2018. SOLA, 15A, 49-54, doi:10.2151/sola. 15A-009.)

\section{Introduction}

From 28 June to 8 July 2018, Japan experienced extreme rainfall particularly over western Japan and Tokai region, with unprecedented precipitation recorded at some Automated Meteorological Data Acquisition System (AMeDAS) stations of the Japan Meteorological Agency (JMA). In some areas, 11-day total precipitation reached two to four times the local monthly climatology for July (Fig. 1). In recognition of the severity and nature of related socio-economic impacts in its peak period from 5 to 7 July, JMA officially named the event "the Heavy Rain Event of July 2018."

Results from a number of case studies (e.g., Kato and Goda 2001; Kato and Aranami 2005; Kato 2006; Tsuguchi and Kato 2014) have suggested primary factors behind localized heavy rainfall events over Japan, including moist airflows with high equivalent potential temperature, potential instability of the ambient atmosphere, and vertical wind shear. Meanwhile, the Baiu front and the associated rainband form under the strong influence of the subtropical jet (STJ) and disturbances propagating along it (Sampe and Xie 2010; Horinouchi 2014). Kosaka et al. (2011) found that interannual variability of the Baiu-Meiyu rainband tends to

Corresponding author: Kazuto Takemura, Japan Meteorological Agency, 1-3-4 Otemachi, Chiyoda-ku, Tokyo, Japan. E-mail: takemura.kazuto@ kugi.kyoto-u.ac.jp.

CThe Author(s) 2019. This is an open access article published by the Meteorological Society of Japan under a Creative Commons Attribution 4.0 International (CC BY 4.0) license (http://creativecommons.org/license/by/4.0).

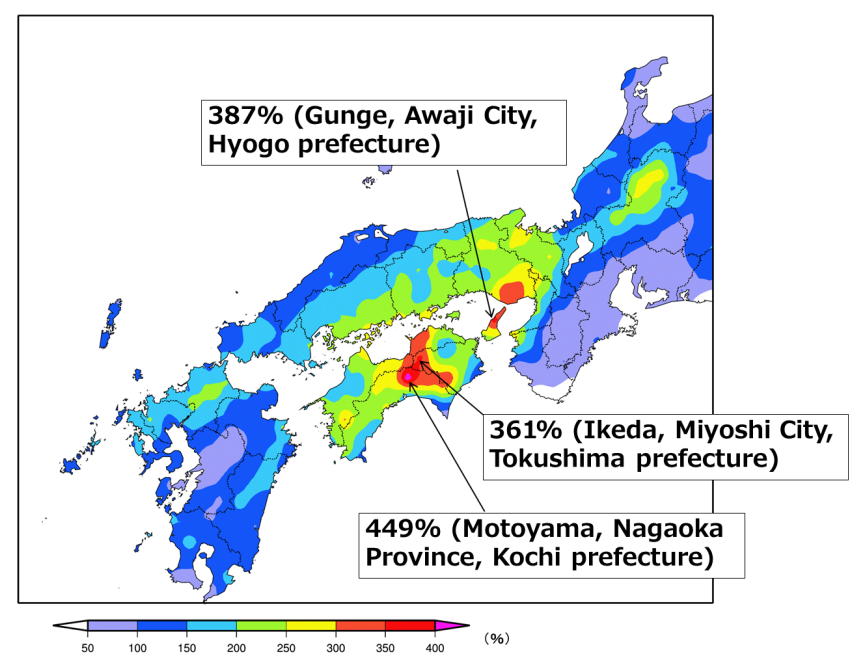

Fig. 1. Ratio (\%) of local cumulative precipitation during the heavy rainfall event (28 June-8 July 2018) to the monthly climatology for July (after JMA 2018).

accompany anomalous mid-tropospheric thermal advection by the STJ, which acts to induce anomalous ascent along the Baiu front (Sampe and Xie 2010), and also found that the anomalous Baiu rainband tends to be related to the "Silk-Road Pattern" - the dominant teleconnection pattern associated with a stationary Rossby wave train propagating along the STJ over the Eurasian continent (Enomoto et al. 2003; Kosaka et al. 2009). The associated STJ meanders with equivalent-barotropic anomalies around Japan thereby modify the strength of the North Pacific Subtropical High (NPSH). It is thus presumed that this particular teleconnection pattern was related to the formation of a quasi-stationary pressure trough to the west of Japan that contributed to the heavy rainfall event.

Preliminary analysis (JMA 2018) regarding the characteristics of the atmospheric circulation that led to the rainfall event was released after an ad hoc meeting of the Advisory Panel on Extreme Climate Events, which consists of experts on climate science from universities and research institutes. The analysis has suggested the dominant factors behind the event, including two prominent moist airstreams into western Japan and persistent ascent associated with the well-defined Baiu front. As an extension of the preliminary analysis included in JMA (2018) and an overview analysis (Shimpo et al. 2019), this study focuses on the persistent convergence of two extremely moist airstreams within western Japan and anomalous atmospheric circulation. Specific attention is paid to (1) event-related anomalous atmospheric circulation that influenced the moist airstreams, (2) simple assessment of relative contributions between anomalous southerlies and large amounts of moisture to the moist airstreams, and (3) influence of active convection over the East China Sea on the enhanced north- 
ward moisture flux. Clarification of the primary factors behind the heavy rain is important in improving awareness toward better operational monitoring and prediction of similar extreme rainfall events in future.

\section{Data and methods}

The JRA-55 reanalysis (Kobayashi et al. 2015) was used in the study to diagnose atmospheric circulation, and COBE-SST (Ishii et al. 2005) was used to determine sea-surface temperature (SST) distribution. In our analysis, "climatology" is defined locally as the average from 1981 to 2010 , and "anomalies" are as deviations from the climatology. The daily Global Rainfall Map (GSMaP) - a near real-time dataset produced and distributed under the Global Rainfall Watch program conducted by the Earth Observation Research Center of the Japan Aerospace Exploration Agency (JAXA; Okamoto et al. 2005) - was also used. Its reanalysis version 6 is available for the 14-year period from 2000 to 2013.

To examine the dynamical relationship between the southward extension of high potential vorticity (PV) air and enhanced ascent, the vertical motion assumed to be induced under the quasigeostrophic (QG) balance was diagnosed with $Q$-vectors (Holton 1992) defined as per Eq. (1) incorporated into the conventional diagnostic equation for vertical motion (i.e., the omega equation).

$$
\boldsymbol{Q} \equiv\left(-\frac{R}{p} \frac{\partial \boldsymbol{v}_{g}}{\partial x} \cdot \nabla T,-\frac{R}{p} \frac{\partial \boldsymbol{v}_{g}}{\partial y} \cdot \nabla T\right) .
$$

Here, $\boldsymbol{v}_{g}$ and $T$ denote geostrophic wind vector and temperature, respectively. Convergence of $Q$-vectors corresponds to dynamically induced ascent and vice versa. For adiabatic flow, vertical motion can be represented solely by $Q$-vector patterns. For practical purposes, $Q$ vectors can be calculated on a given isobaric surface by using geopotential and temperature taken from JRA-55.

To assess the relative importance of wind and moisture anomalies in the enhanced moisture flux convergence observed during the heavy rainfall event, a simple budget analysis of moisture flux $q \boldsymbol{v}$ based on JRA-55 was performed. The flux can be simply decomposed as

$$
q \boldsymbol{v}=\left(\bar{q}+q^{\prime}\right)\left(\overline{\boldsymbol{v}}+\boldsymbol{v}^{\prime}\right)=\bar{q} \boldsymbol{v}+\bar{q} \boldsymbol{v}^{\prime}+q^{\prime} \overline{\boldsymbol{v}}+q^{\prime} \boldsymbol{v}^{\prime} .
$$

Here $q$ and $\boldsymbol{v}$ denote specific humidity and horizontal wind vector, respectively, and $\bar{A}$ and $A^{\prime}$ indicate the climatology and anomaly, respectively, of a given variable $A$. On the RHS of Eq. (2), the first and fourth terms are climatological and anomaly self-interaction terms, respectively, whereas the second and third terms represent cross-interaction between climatological values and anomalies in wind and moisture.

To estimate the contribution of persistent active convection observed over the East China Sea (ECS) to the maintenance of the stronger-than-normal southwesterlies in the lower- and mid-troposphere, a PV budget analysis was performed based on the Ertel's PV equation:

$$
\frac{\partial P}{\partial t}=-\boldsymbol{v} \cdot \nabla_{\theta} P+\frac{P}{\sigma} \frac{\partial}{\partial \theta}(\sigma \dot{\theta})+F
$$

Here, $P, \boldsymbol{v}, \theta$ and $\sigma$ denote $\mathrm{PV}$, wind vectors, potential temperature, and static stability (defined as $\sigma \equiv-g^{-1} \partial p / \partial \theta$ ), respectively, on a given isentropic surface, while diabatic heating is defined as $\dot{\theta} \equiv D \theta / D t$. The term $F$ signifies other non-conservative processes, including frictional forcing. By evaluating the local time tendency of PV represented as the LHS of (3) and the PV advection as the first term on the RHS from the reanalysis data, the diabatic heating effect can be crudely estimated as the residual under the assumption of the negligible frictional term $F$ and a small Rossby number (Hoskins 1991). This assumption is valid for large- and synoptic-scale atmospheric circulation in the free troposphere as targeted in this study.

\section{Results}

Figure 2 shows GSMaP precipitation, SST anomalies and surface latent heat flux (LHF) over the western North Pacific in the three-day period from 5 to 7 July 2018 (the peak time of the heavy rainfall event). As is evident in Fig. 2a, a well-defined rainband formed over the ECS and mainland Japan. Maximum rainfall over western Japan and Tokai region well exceeded $80 \mathrm{~mm} /$ day (red

\section{(b) SST anom.}

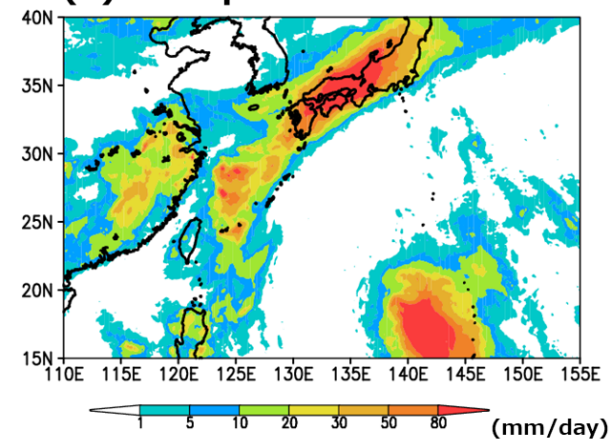

(c) Latent Heat Flux anom.

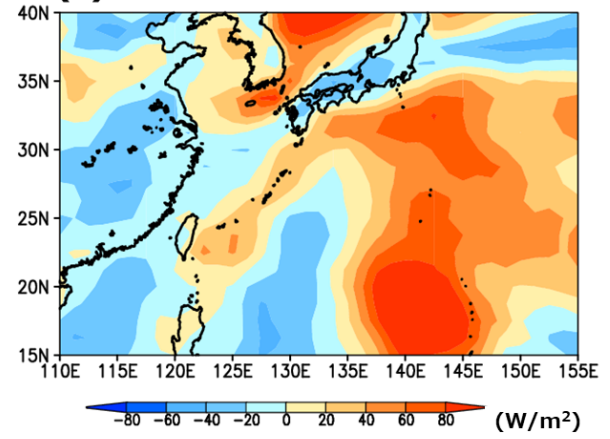

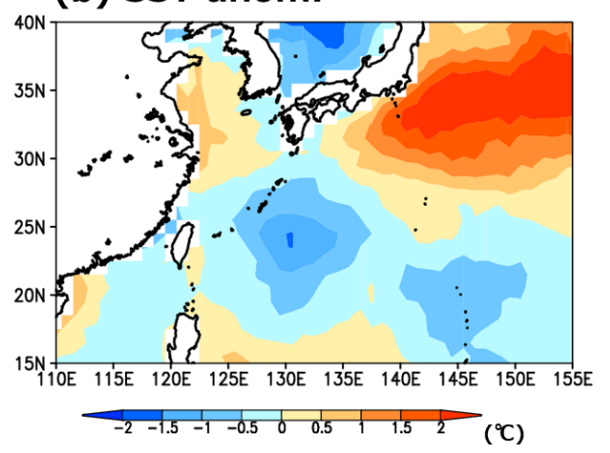

Fig. 2. Three-day mean (a) GSMaP precipitation (mm/day), (b) SST anomalies $\left({ }^{\circ} \mathrm{C}\right)$ and $(\mathrm{c})$ JRA-55 surface LHF anomalies $\left(\mathrm{W} / \mathrm{m}^{2}\right)$ over the western North Pacific from 5 to 7 July 2018. 
(a) Z200

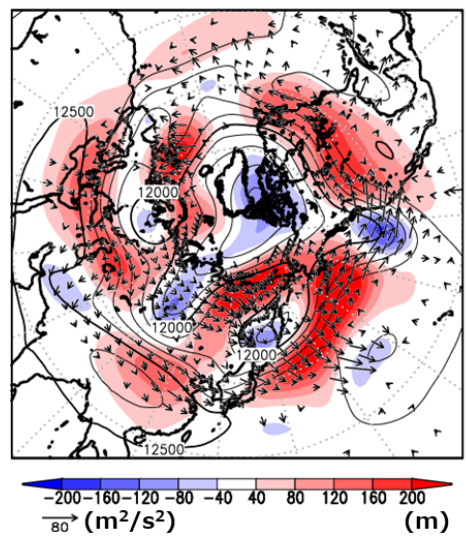

(b) SLP

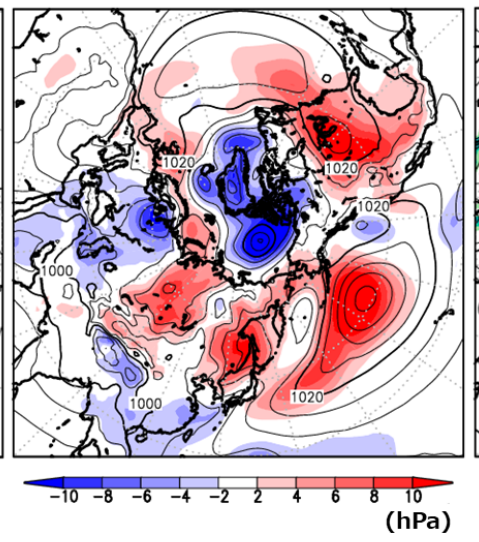

(c) EPT925

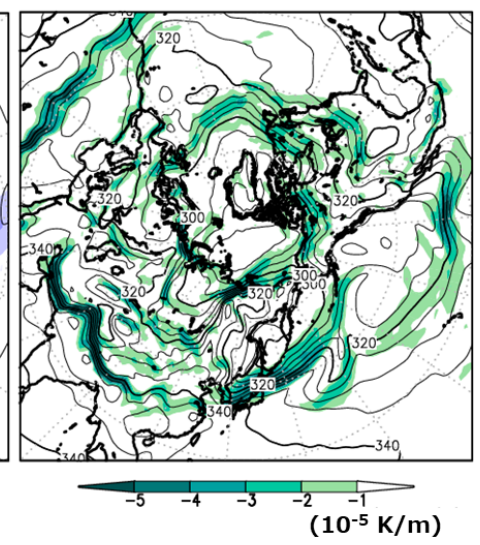

Fig. 3. As in Fig. 2, but for (a) 200-hPa height (contour interval: $100 \mathrm{~m}$ ) and related anomalies (shading), wave-activity flux after Takaya and Nakamura (2001) (arrows; unit: $\mathrm{m}^{2} / \mathrm{s}^{2}$ ), (b) sea-level pressure (contour interval: $4 \mathrm{hPa}$ ) and related anomalies (shading), and (c) 925-hPa equivalent potential temperature (contour interval: $5 \mathrm{~K}$ ) and related equatorward gradient (shading) over the extratropical Northern Hemisphere. The basic state to calculate the wave activity flux is defined as the climatology. In (c), shading is applied where the gradient exceeds $1 \times 10^{-5} \mathrm{~K} / \mathrm{m}$ to highlight well-defined near-surface fronts.

shading in Fig. 2a), approximately equivalent to above $600 \%$ of the corresponding 14-year (from 2000 to 2013) local climatology (not shown). This extreme rainfall suggests an inflow of extremely moist air into the area. In Fig. 2b, negative SST anomalies were observed over the subtropical western North Pacific around the Okinawa Islands to the south of the Kyushu Island of Japan. These anomalies developed after the passage of Typhoon Prapiroon (T1807) under enhanced surface southerlies during the heavy rainfall event, as discussed below. Though generally weak, upward LHF was stronger than its climatology around the Okinawa Island and off the southern coast of mainland Japan (Fig. 2c), indicating enhanced moisture supply from the warm Kuroshio current.

Figure 3 shows the corresponding three-day mean fields of atmospheric circulation over the extratropical Northern Hemisphere. The 200-hPa height field shown in Fig. 3a indicates largeamplitude meanders of the upper-tropospheric polar-front jet (PFJ; see the contour line for 12,000 m) and STJ (see the contour line for $12,400 \mathrm{~m}$ ). The meanders were associated with quasi-stationary Rossby wave trains, as diagnosed with the wave-activity flux (Takaya and Nakamura 2001) in Fig. 3a. Local breaking of one of those wave trains was manifested as a prominent meander of the upper-level PFJ with an intensified blocking high over Eastern Siberia and a trough to the south (Fig. 3a), leading to the marked development of the surface Okhotsk High (Fig. 3b; Nakamura and Fukamachi 2004). Another wave train along the STJ accompanied an upper-level trough over the Korean Peninsula and a ridge to the east of Japan (Fig. 3a) in the condition of marked persistent tropospheric warmness over the Northern Hemisphere mid-latitude (i.e., positive height anomalies in a wide area of mid-latitude; Shimpo et al. 2019), as a manifestation of the Silk Road teleconnection across the Eurasian continent (Enomoto et al. 2003; Kosaka et al. 2009). The upper-level ridge was associated with the enhanced westward extension of the surface NPSH toward Japan (Fig. 3b). As shown in Fig. 3c, the meridional gradient of 925-hPa equivalent potential temperature was enhanced over Japan along the Baiu front, where cool northeasterlies and warm, moist southerlies were confluent between the two intensified high-pressure systems (Fig. 3b).

Figure 4 shows daily fields of $350-\mathrm{K}$ isentropic PV, $500-\mathrm{hPa}$ $Q$-vectors and their divergence for the 5-7 July period. The upperlevel trough deepening over the Korean Peninsula seen in Fig. 3 a accompanied pronounced southward intrusion of high-PV air (contoured in Fig. 4). To its south and southeast, the $Q$-vectors were convergent over western Japan at $500 \mathrm{hPa}$ (vectors and shading in Fig. 4) and $850 \mathrm{hPa}$ (not shown). The convergence remained strong throughout the rain event, maximizing around the peak time on 6 July. Figure 4 indicates that the high-PV air associated with the upper-level trough acted to induce ascent dynamically around the Baiu front, thereby contributing to the heavy rainfall event over western Japan.

Figures 5a and 5b compare vertically-integrated moisture flux and precipitation estimated from the flux convergence during the rainfall event with their climatological counterpart. The comparison highlights the profound enhancement of southwesterly moisture flux in the area from around the Okinawa Islands to mainland Japan, which yielded a band of extremely enhanced moisture convergence over western Japan (shading in Fig. 5a). The moisture flux appears to consist of two branches, as suggested by the vertical profiles for the meridional component of the flux to the south of mainland Japan (not shown). One is a lower/mid-tropospheric southwesterly airstream with a deep structure, which was seemingly related to active convection over the ECS yielding locally enhanced precipitation (Fig. 2a). The other is a lower-tropospheric southerly airstream along the western fringe of the intensified surface NPSH (Fig. 3b). As shown in Fig. 5c, the horizontal moisture flux convergence within the domain $31.25^{\circ} \mathrm{N}-35^{\circ} \mathrm{N}, 130^{\circ} \mathrm{E}-135^{\circ} \mathrm{E}$ from 5 to 7 July 2018 was the strongest in any three-day periods since 1958. This unprecedented moisture convergence, which led to the extreme rainfall event, occurred under the quasi-stationary Baiu front that formed between the intensified high-pressure systems, as shown in Fig. 3.

The time evolution showing the convergence of individual components of the vertically integrated moisture flux (Fig. 5d) based on Eq. (2) leads to an assessment of the relative importance of wind and moisture anomalies in the enhanced moisture flux convergence over western Japan. In the peak period of the rainfall event, the profound moisture flux convergence primarily reflected an overwhelming contribution from wind anomalies (orange line in Fig. 5d). The corresponding contribution from moisture anomalies (dashed blue line) was much smaller and peaked before the rainfall event. The dominant contribution from wind anomalies confirms the vital importance of the two moist airstreams and their persistent convergence related to enhanced convection over the ECS and the intensified NPSH (Fig. 5a). In contrast, the selfinteraction term between wind and moisture anomalies (dashed red line) significantly contributed to moisture flux divergence, counteracting contributions from the other terms. The moisture flux divergence may include a contribution from enhanced evaporation over the warm Kuroshio current (Fig. 2c; Sekizawa et al. 2019).

PV budget analysis was performed to crudely estimate the contribution from the enhanced convection over the southern ECS to the maintenance of the low-level southwesterlies that transported abundant moisture toward western Japan. Anomalies in 
(a) July 5

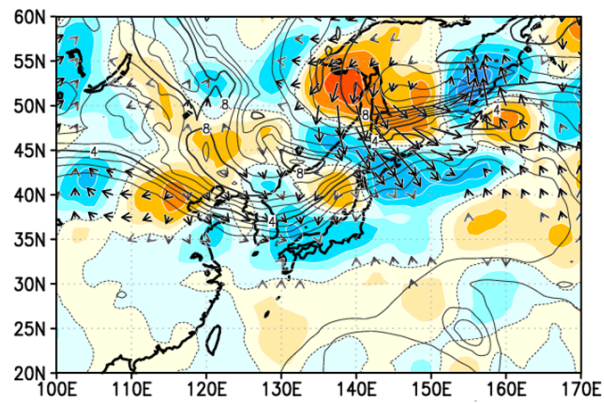

(c) July 7

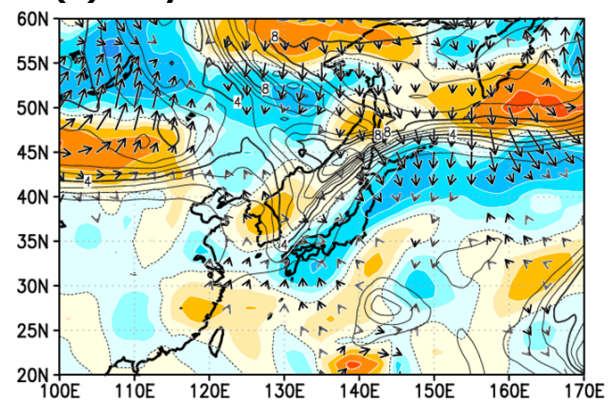

(b) July 6

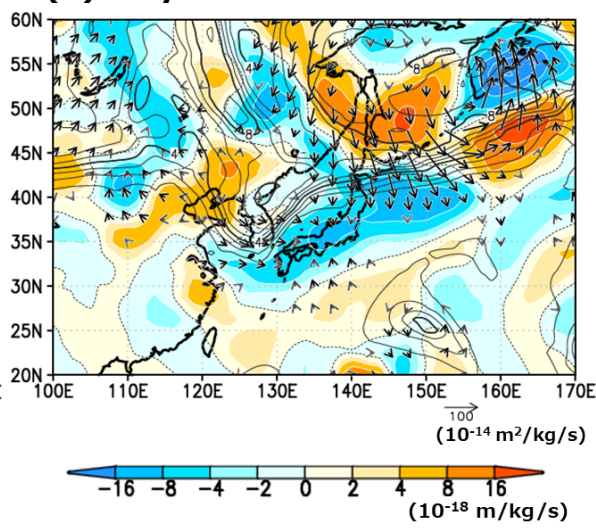

Fig. 4. 350-K isentropic PV (contours), 500-hPa $Q$-vectors (unit: $\mathrm{m}^{2} / \mathrm{kg} / \mathrm{s}$ ) and related divergence (shading; unit: $\mathrm{m} / \mathrm{kg} / \mathrm{s}$ ) derived from daily means for (a) 5, (b) 6 and (c) 7 July 2018. Contour intervals are 1 PVU. Q-vectors smaller in magnitude than $10 \times 10^{-14} \mathrm{~m}^{2} / \mathrm{kg} / \mathrm{s}$ are omitted. Red and blue shading indicates $Q$-vector divergence and convergence, respectively.

(a) WVF (Analysis)

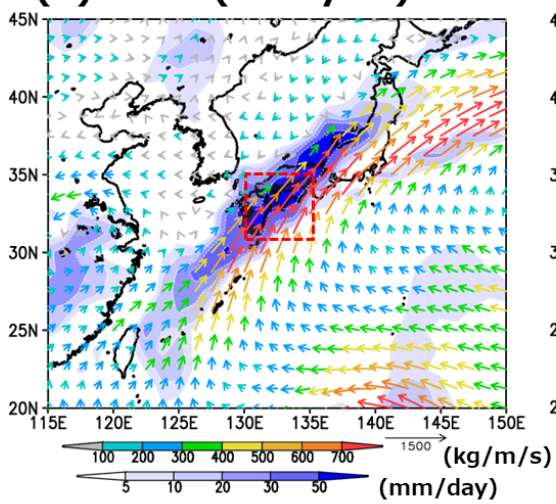

(c) WVF Divergence

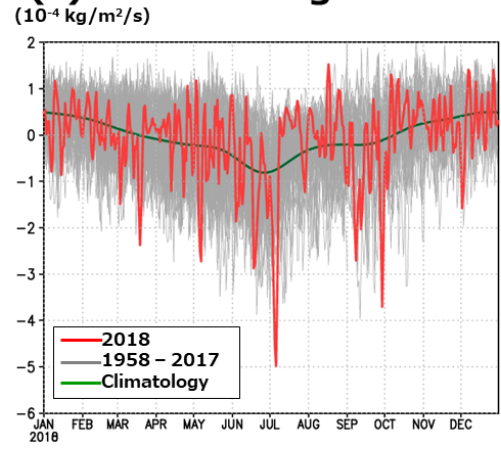

\section{(b) WVF (Climatology)}

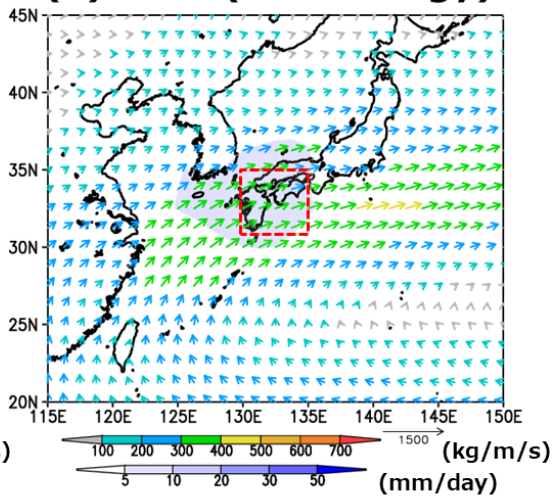

(d) WVF Budget

$\left(10^{-4} \mathrm{~kg} / \mathrm{m}^{2} / \mathrm{s}\right)$

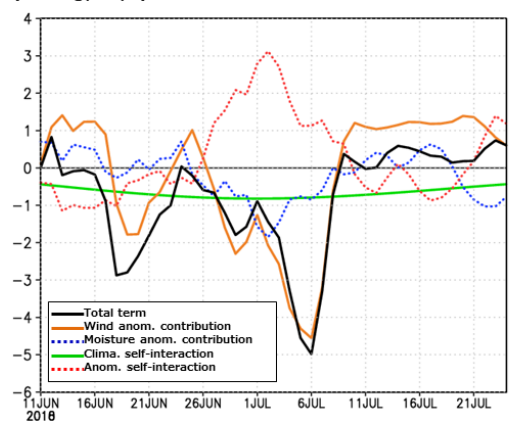

Fig. 5. (a) Vertically integrated horizontal moisture flux (vectors; unit: $\mathrm{kg} / \mathrm{m} / \mathrm{s}$ ) and precipitation estimated from the flux convergence (blue shading; unit: $\mathrm{mm} /$ day) in the three-day period from 5 to 7 July 2018, (b) the corresponding climatology for the same dates, and (c) three-day running-mean timeseries of vertically integrated moisture flux divergence $\left(10^{-4} \mathrm{~kg} / \mathrm{m}^{2} / \mathrm{s}\right)$ within $\left[31.25^{\circ} \mathrm{N}-35^{\circ} \mathrm{N}, 130^{\circ} \mathrm{E}-135^{\circ} \mathrm{E}\right]$, the domain marked as dashed red lines in (a)-(b). Red, grey and green lines represent annual timeseries for 2018, other individual years from 1958 to 2017 and the climatology, respectively. (d) As in (c), but for 11 June to 25 July 2018 (black) and related decomposition based on Eq. (2) Solid orange, dashed blue, solid green and dashed red lines indicate the total term (as in the red line in (c)), wind anomaly contribution, moisture anomaly contribution, and self-interaction term between the climatology and anomalies, respectively. The vertical integration in (a) (d) is taken from the surface to the $300-\mathrm{hPa}$ level.
Ertel's PV and winds on a lower-tropospheric $(310 \mathrm{~K})$ isentropic surface during the peak period of the rainfall event (Fig. 6a) were characterized by a SW-NE-oriented band of high-PV anomalies that almost coincided with the precipitation band shown in Fig. 2a. The band of high-PV anomalies accompanied cyclonic anomalies over the ECS, where convection was locally enhanced. Presumably, the cyclonic anomalies may have contributed to the lower- to mid-tropospheric anomalous southwesterly flow (Fig. 5a). The longitudinal sections in Fig. 7 show the results of our PV budget analysis based on Ertel's PV equation (3) after averaged within the $20^{\circ} \mathrm{N}-30^{\circ} \mathrm{N}$ band. Estimated as the difference between the PV time tendency (Fig. 7a) and the PV advection term (Fig. 7b), the residual term (Fig. 7c) exhibits a pair of low- and high-PV tendencies in the upper and lower troposphere above and below the $340 \mathrm{~K}$ isentropic surface, respectively, around $125^{\circ} \mathrm{E}$. These signatures in the residual term is consistent with the PV generation by the enhanced convection. Note that a well-defined positive anomaly in convective heating rate obtained as a model-forecasted product in JRA-55 appears to be unrealistically elevated (not shown) consistently with the particular tendency for JRA-55 to 
(a) 310K PV\&UV anom.

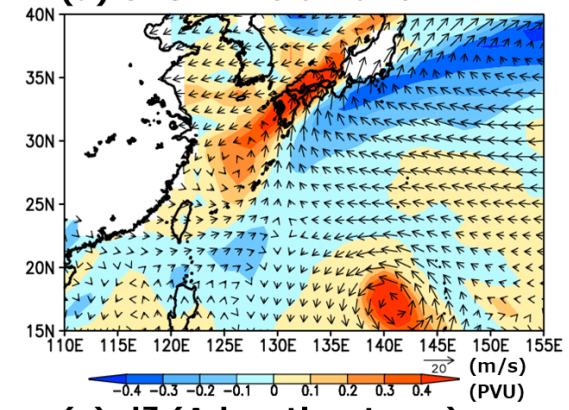

(c) $d \zeta$ (Advection term)

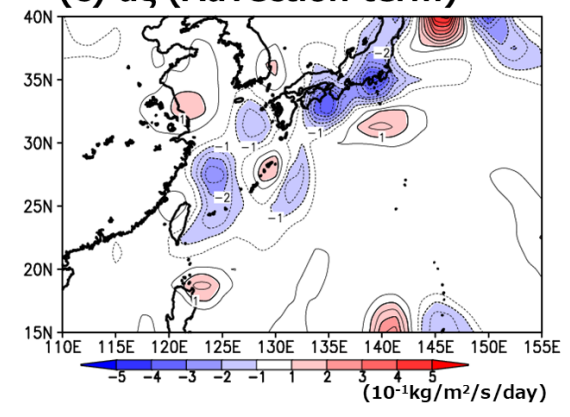

(b) $\zeta$ (anom.)

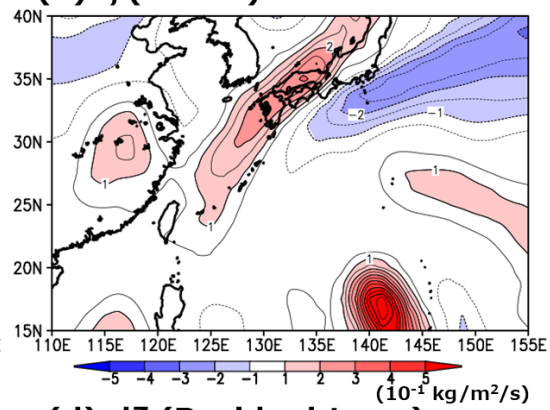

(d) d ( Residual term)

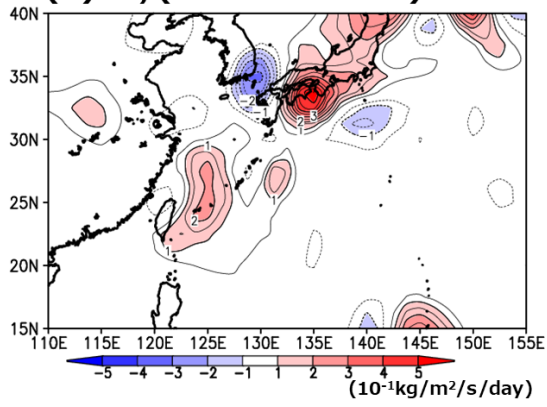

Fig. 6. As in Fig. 2, but for (a) anomalies in PV (shading; unit: PVU) and wind (vectors; unit: $\mathrm{m} / \mathrm{s}$ ) on the $310-\mathrm{K}$ isentropic surface, and vertically integrated (b) relative vorticity anomalies $\left(10^{-1} \mathrm{~kg} / \mathrm{m}^{2} / \mathrm{s}\right)$ and $(\mathrm{c}-\mathrm{d})$ anomalous relative vorticity tendencies per day $\left(10^{-1} \mathrm{~kg} / \mathrm{m}^{2} / \mathrm{s} /\right.$ day $)$. (c) and (d) are calculated from the PV advection and residuals terms, respectively, of the PV budget analysis (i.e., Figs. $7 \mathrm{~b}$ and $7 \mathrm{c}$ ). The vertical integration in (b) (d) is taken from the surface to the $500-\mathrm{hPa}$ level.

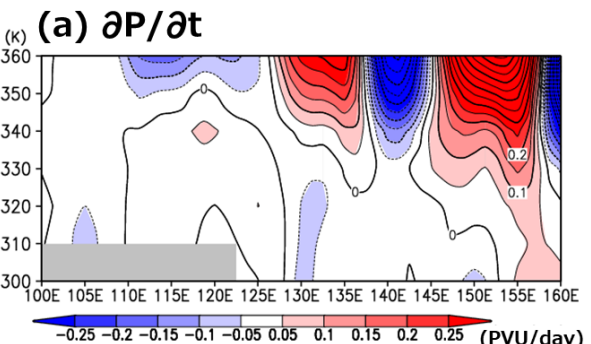

(c) Residual term

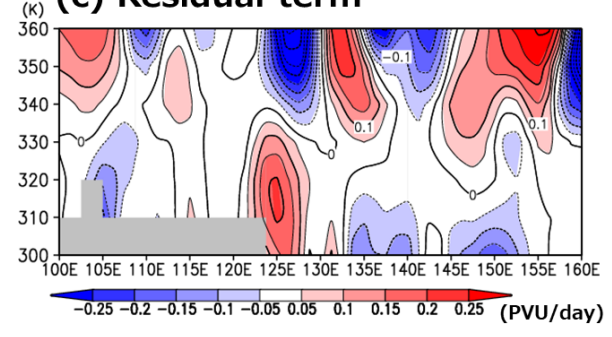

(b) Advection term

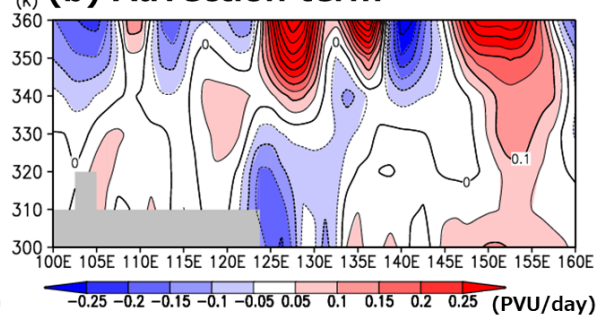

Fig. 7. Longitude-isentrope sections of (a) anomalous PV tendency, (b) anomalous PV advection, and (c) residual term evaluated as (a)-(b) as averages over $20^{\circ} \mathrm{N}-30^{\circ} \mathrm{N}$ from 5 to 7 July 2018 calculated from JRA-55 isentropic data. The unit in (a) (c) is PVU/day. Gray shading is applied where a reanalysis value is unavailable for calculating time and spatial derivatives where isentropes are below the surface.

overestimate deep convective systems (Kobayashi et al. 2015). Under the assumption of the negligible frictional term ( $F$ in Eq. 3$)$, this result qualitatively suggests that diabatic heating associated with active convection over the ECS acted to induce the high-PV tendency and thus maintain the cyclonic circulation anomalies in the lower troposphere (Hoskins et al. 1985), contributing to the maintenance of the low-level southwesterly moist airstream (Fig. 5a). As shown in Fig. 6d, the anomalous tendency in relative vorticity as estimated from the residual term on the PV budget (Fig. 7c), after calculating tendency of relative vorticity with an assumption of the negligible small tendency of static stability, expanding on isobaric coordinate and then mass-weighted vertical integration on the pressure level below the $500-\mathrm{hPa}$, also suggests that cyclonic circulation anomalies can be induced in the lower and mid-troposphere by enhanced convection over the ECS. Compared with its reanalysis counterpart (Fig. 6b), the effect of active convection is nearly twice as large as the actual anomalies and therefore can be considered to play an important role in offsetting the effect of the anomalous PV advection (Figs. 6c and 7b) and thus maintaining the southwesterly flow.

\section{Summary and discussion}

This study offers detailed investigation of primary factors behind the extreme rainfall event centered over western Japan from 5 to 7 July 2018 as a follow-up of the preliminary analysis conducted by the JMA Advisory Panel on Extreme Climate Events (JMA 2018). The atmospheric circulation pattern observed during the event was characterized by a well-defined quasi-stationary Baiu front in the vicinity of western Japan. The front formed between the prominent surface Okhotsk High and NPSH, which developed in association with a blocking flow configuration with a marked meander of the PFJ and the meandered STJ, respectively. Southward high-PV intrusion with an amplified upper-level trough over the Korean Peninsula dynamically induced ascent along the Baiu front. During the peak period of the event, prominent moisture inflow into western Japan was characterized by a shallow southerly airstream enhanced by the surface NPSH and a deeper southwesterly airstream influenced by enhanced convection over the southern ECS. The vertically integrated moisture flux with 
those airstreams yielded the strongest convergence observed over western Japan in the last 60 years. The extreme moisture flux convergence was primarily associated with a massive contribution from the enhanced anomalous southerlies. The deep convection over the southern ECS is considered to contribute positively to the maintenance of the southwesterly airstream by generating low-level cyclonic PV anomalies. This conclusion is, however, based on a conversion from isentropic PV tendencies to isentropic vorticity tendencies as shown in Figs. $6 \mathrm{c}$ and $6 \mathrm{~d}$ for simplicity, but this crude method can induce certain errors in our estimation. The standard PV inversion (e.g., Hakim et al. 1996) with a given quasigeostrophic (QG) PV anomalies is more appropriate and should thus be used for reevaluating our estimation in future study.

Although the above results suggest an important contribution from the enhanced convection over the southern ECS to the extreme moisture inflow toward western Japan, specific dynamical mechanisms for the triggering, development and persistence of the convection still remain to be elucidated. Further investigation is needed, in particular to assess the significance of the influence of tropical intraseasonal variability and monsoonal westerlies. Furthermore, our analysis cannot feature the importance of mesoscale convective rainbands that influenced fatal sediment disasters more directly during the rainfall event. Thus, meso-scale analyses are required to seek the linkage of those rainbands with the synoptic-scale characteristics elucidated in this study. For example, analysis of radar and satellite measurements, diagnosis of high-resolution regional analysis data and hindcast experiments with a high-resolution regional model will be useful for clarifying the meso-scale behavior of precipitation systems over western Japan and assess the predictability of the rainfall event. In addition, comparison will also be useful between the July 2018 event and other extreme rainfall events, including the wide-area rainfall of July 1972 and a more localized intense event over the northern Kyushu Island observed in July 2017.

JMA (2018) suggested that a long-term increasing trend in water vapor amount over Japan under the global warming may have contributed to the Heavy Rainfall Event of 2018. Our analysis of moisture flux convergence suggests only a minor contribution from moisture anomalies to the extreme rainfall over western Japan. Still, the particular contribution is positive, acting to increase the observed convergence by $\sim 15 \%$ (dashed blue line in Fig. 5d). However, this is a crude estimate, and further investigation is needed with approaches such as pseudo-warming experiments regarding the rainfall event with a high-resolution regional model.

\section{Acknowledgements}

The authors are grateful to the two anonymous reviewers for their constructive comments and the members of the JMA Advisory Panel on Extreme Climate Events, who provided useful information for this study. The GSMaP dataset was provided by JAXA Global Rainfall Watch, and was produced and distributed by the Earth Observation Research Center of the Japan Aerospace Exploration Agency. The author $\mathrm{HN}$ is supported in part by the Japan Society for the Promotion of Science through KAKENHI Grants (18K19951, 16H01844) and by the Japan Science and Technology Agency through Belmont Forum CRA "InterDec."

Edited by: M. Yoshizaki

\section{References}

Enomoto, T., B. J. Hoskins, and Y. Matsuda, 2003: The formation mechanism of the Bonin high in August. Quart. J. Roy. Meteor. Soc., 129, 157-178.

Hakim, G., D. Keyser, and L. Bosart, 1996: The Ohio Valley wavemerger cyclogenesis event of 25-26 January 1978. Part II: Diagnosis using quasigeostrophic potential vorticity inversion. Mon. Wea. Rev., 124, 2176-2205.
Holton, J. R., 1992: An Introduction to Dynamic Meteorology, 3rd ed., Academic Press, 507 pp.

Horinouchi, T., 2014: Influence of upper tropospheric disturbances on the synoptic variability of precipitation and moisture transport over summertime East Asia and the northwestern Pacific. J. Meteor. Soc. Japan, 92, 519-541.

Hoskins, B. J., M. E. McIntyre, and A. W. Robertson, 1985: On the use and significance of isentropic potential vorticity maps. Quart. J. Roy. Meteor. Soc., 111, 877-946.

Hoskins, B. J., 1991: Towards a PV- $\theta$ view of the general circulation. Tellus A, 43, 27-36.

Ishii, M., A. Shouji, S. Sugimoto, and T. Matsumoto, 2005: Objective analyses of sea-surface temperature and marine meteorological variables for the 20th Century using ICOADS and the Kobe Collection. Int. J. Climatol., 25, 865-879.

JMA, 2018: Primary factors behind the Heavy Rain Event of July 2018 and the subsequent heatwave in Japan from mid-July onward. Press Release of Tokyo Climate Center (Available online at https://ds.data.jma.go.jp/tcc/tcc/news/press_2018 0822.pdf, accessed 22 March 2019).

Kato, T., and K. Aranami, 2005: Formation factors of 2004 Niigata-Fukushima and Fukui heavy rainfalls and problems in the predictions using a cloud-resolving model. SOLA, 1, $1-4$.

Kato, T., 2006: Structure of the band-shaped precipitation system inducing the heavy rainfall observed over northern Kyushu, Japan on 29 June 1999. J. Meteor. Soc. Japan, 84, 129-153.

Kato, T., and H. Goda, 2001: Formation and maintenance processes of a stationary band-shaped heavy rainfall observed in Niigata on 4 August 1998. J. Meteor. Soc. Japan, 79, 899-924.

Kobayashi, S., Y. Ota, Y. Harada, A. Ebita, M. Moriya, H. Onoda, K. Onogi, H. Kamahori, C. Kobayashi, H. Endo, K. Miyaoka, and K. Takahashi, 2015: The JRA-55 reanalysis: General specifications and basic characteristics. J. Meteor. Soc. Japan, 93, 5-48.

Kosaka, Y., H. Nakamura, M. Watanabe, and M. Kimoto, 2009: Analysis on the dynamics of a wave-like teleconnection pattern along the summertime Asian jet based on a reanalysis dataset and climate model simulations. J. Meteor. Soc. Japan, 87, 561-580.

Kosaka, Y., S.-P. Xie, and H. Nakamura, 2011: Dynamics of interannual variability in summer precipitation over East Asia. $J$. Climate, 24, 5435-5453.

Nakamura, H., and T. Fukamachi, 2004: Evolution and dynamics of summertime blocking over the Far East and the associated surface Okhotsk high. Quart. J. Roy. Meteor. Soc., 130, 1213-1233.

Okamoto, K., T. Iguchi, N. Takahashi, K. Iwanami, and T. Ushio, 2005: The global satellite mapping of precipitation (GSMaP) project. 25th IGARSS Proc., 3414-3416.

Sampe, T., and S.-P. Xie, 2010: Large-scale dynamics of the Meiyu-Baiu rainband: Environmental forcing by the westerly jet. J. Climate, 23, 113-134.

Sekizawa, S., T. Miyasaka, H. Nakamura, A. Shimpo, K. Takemura, and S. Maeda, 2019: Anomalous moisture transport and oceanic evaporation during a torrential rainfall event over western Japan in early July 2018. SOLA, 15A, 25-30.

Shimpo, A., and co-authors, 2019: Primary factors behind the Heavy Rain Event of July 2018 and the subsequent heat wave in Japan. SOLA, 15A, 13-18.

Takaya, K., and H. Nakamura, 2001: A formulation of a phaseindependent wave-activity flux for stationary and migratory quasi-geostrophic eddies on a zonally varying basic flow. $J$. Atmos. Sci., 58, 608-627.

Tsuguti, H., and T. Kato, 2014: Contributing factors of the heavy rainfall event at Amami-Oshima Island, Japan, on 20 October 2010. J. Meteor. Soc. Japan, 92, 163-183.

Manuscript received 22 March 2019, accepted 15 June 2019 SOLA: https://www.jstage.jst.go.jp/browse/sola/ 